\title{
ATUAÇÃO DA ASSOCIAÇÃO BRASILEIRA DE ENFER- MAGEM JUNTO AO PROGRAMA INTENSIVO DE PREPARO DE MÃO-DE-OBRA, DO MINISTERIO DA EDUCAÇÃO E CULTURA
}

\author{
Ieda Barreira e Castro *
}

\author{
I N T R O D U Ç Ã O
}

Entre as quatro grandes prioridades estabelecidas na publicação "Metas e Bases para a Ação do Governo", referentes ao período 1970-1973, está a "Revolução na Educação e Aceleração do Programa de Saúde e Saneamento". Do elenco de projetos prioritários no Setor Educação consta a "Expansão do Programa Intensivo de Preparo de Mão-de-Obra (PIPMO): a experiência do PIPMO Programa Intensivo de Preparação de Mão-de-Obra, na área do Ensino Industrial, será estendida aos setores primário e terciário... No que se refere ao setor terciário, as atividades serão concentradas nas áreas da saúde.

Os recursos para a implementação do programa, no período, estão orçados em cerca de $\operatorname{Cr} \$ 64$ milhões."

No mesmo ano de 1970, a Presidente da ABEn compareceu à Reunião Nacional dos Grupos - Tarefa das Coordenações do PIPMO, realizada em Brasília de 28 a 31 de julho. Neste mesmo mês havia ela declarado em seu Relatório Anual (julho 1969 - junho 1970), apresentado na Assembléia de Delegados, na Cidade de São Paulo: "por solicitação do Sr. Coordenador do PIPMO, a ABEn enviou sugestões para o programa dos cursos de Instrumentação Cirúrgica, que serão financiados pelo MEC, sob a forma de convênios com escolas de enfermagem, com hospitais, com a própria ABEn, nas suas Seções Estaduais.

(*) 1. ${ }^{\text {a }}$ Secretária da ABEn Central. Supervisora da Divisão Nacional de Tuberculose - M.S. 
Este programa, originariamente do MTPS, inclui também o preparo de atendentes em cursos rápidos. As Seções da ABEn devem estar preparadas para colaborar com os organismos do MEC na seleção das instituições em condições de estabelecer convênios para esse fim (hospitais ou escolas de enfermagem, de técnicos ou de auxiliares de enfermagem), para assessorar as enfermeiras que integrarem o programa, ou mesmo para firmar os convênios e oferecer os cursos previstos, através de suas Comissões de Educação e Assistência de Enfermagem".

Após um ano, a colaboração da ABEn já se fazia de modo regular, tanto em nível central como em nível estadual. 0 assunto constou da ordem do dia da primeira e da segunda Reuniões Ordinárias da Diretoria, realizadas em março e maio de 1971. Nesta época, já estavam em elaboração Manuais para o Treinamento de Atendentes, conforme convênio firmado entre o Instituto Presidente Castello Branco, Ministério da Saúde e o PIPMO/MEC, para as principais áreas dos Serviços de Enfermagem.

Na Assembléia de Delegados de 1971, realizada em julho, em Manaus, a Presidente da ABEn, no seu Relatório Anual (julho de 1970 junho de 1971), na parte referente ao trabalho desenvolvido pelas Seções Estaduais, mencionou a colaboração prestada pelas Seções da Bahia, Estado do Rio de Janeiro, Guanabara e São Paulo ao PIPMO.

Na XII Reunião Nacional dos Grupos - Tarefa das Coordenações do PIPMO, realizada em Brasília, de 22 a 25 de fevereiro, a ABEn se fez representar na pessoa de sua $2 .^{a}$-Vice-Presidente; outras 4 enfermeiras participaram da Reunião representando diversas instituições.

\section{JUSTIFICATIVA}

Sentindo que um levantamento da situação da ABEn junto ao PIPMO é assunto do maior interesse para a classe, pois representa a participação da nossa Associação em um programa prioritário do Governo Federal, que constitui mais uma contribuição da mesma para a melhoria do padrão de assistência de enfermagem no País, certificamo-nos junto à Diretoria da ABEn Central da inexistência de iniciativa neste sentido e deliberamos proceder ao levantamento dos dados, visando a apresentação dos resultados como Tema Livre no XXIV Congresso Brasileiro de Enfermagem. Para isto enviamos carta circular às Seções, nos primeiros dias do mês de abril. Como até o dia 16 de junho havíamos recebido resposta somente de 7 seções (um terço do total), o que impossibilitava a realização do trabalho, remetemos outra carta circular expondo a situação e co- 
municando que o levantamento, mesmo parcial, seria apresentado sob a forma de Relatório, na Assembléia de Delegados. No momento reiteramos o pedido às Seções em falta. Após a segunda circular recebemos resposta de 3 Seções o que perfez um total de 10. Entretanto, na ocasião da Terceira Reunião Ordinária de 1972, da Diretoria da ABEn Central a Cordenadora da Comissão de Temas do XXIV Congresso Brasileiro de Enfermagem, D. Anayde Corrêa de Carvalho, julgou ser do interesse da ABEn que estes resultados fossem divulgados a um maior número de pessoas e por isto foi deliberado que o trabalho fosse apresentado mesmo como Tema Livre.

\section{RESULTADOS}

A Ação das Seções Estaduais da ABEn junto às Coordenações do PIPNIO se fez notar mais acentuadamente a partir do $2 .^{\circ}$ semestre de 1971, época em que foram desenvolvidos todos os cursos por elas organizados.

Das 10 Seções que responderam o questionário, 4 não vêm atuando junto ao PIPMO. Como justificativa, uma (PA) declarou que existe convênio entre o PIPMO e a Secretaria de Saúde e uma (PE), entre o PIPMO e a Universidade Federal. Duas não apresentaram justificativa (BA e RS).

Das 6 que atuam ( $\mathrm{RN}, \mathrm{AL}, \mathrm{SE}, \mathrm{GB}, \mathrm{RJ}$ e $\mathrm{SC})$, apenas duas têm convênio firmado ( $\mathrm{GB}$ e RJ). Todas 6 vêm organizando cursos; 3 fazem análise de projetos de cursos ( $\mathrm{SE}, \mathrm{GB}$ e RJ), 2 selecionam instituições para convênio com o PIPMO e dão assessoria geral (SE e RJ) .

As dificuldades encontradas pelas Seções para melhor atuar junto ao PIPMO são: falta de enfermeiras disponíveis para ministrar aulas (SE, RJ e SC), dificuldades administrativas (RJ e SC) e dificuldades relacionadas à parte contábil e financeira (GB).

\section{T A B E L A 1}

Dentre as Seções que responderam o questionário, a que vem trabalhando mais intensamente neste setor é a do Estado do Rio, que desenvolveu mais da metade do trabalho executado pelas Seções, em número de cursos, 13 em $23(56,7 \%)$, carga horária, 4.000 em 7.172 horas $(55,8 \%)$, e no número de pessoas treinadas, $246 \mathrm{em}$ $414(59,5 \%)$. Em segundo lugar vem a Seção de Sergipe com 4 cursos $(17,4 \%), 2.291(31,9 \%)$ e 49 alunos $(11,8 \%)$. 
T A B E L A 2

Os 23 cursos desenvolvidos enquadram-se em 6 denominações sendo 18 de atendentes e/ou auxiliar de serviços médicos (78,5\%), 1 de Visitadoras, 1 de Primeiros Socorros, 1 de Curiosas, 1 de Instrumentação Cirúrgica e 1 de Metodologia de Pesquisa Aplicada à Enfermagem. Dos 414 alunos, $325(\mathbf{7 8 , 6 \%})$ foram dos cursos de atendentes. Apenas 3 cursos se destinavam à preparação de pessoal $(13,0 \%)$ : o de Instrumentação Cirúrgica, o de Visitadoras e 1 de Atendentes. Os 17 restantes cursos de atendentes foram de pessoal já em função $(94,5 \%)$ bem como o de Primeiros Socorros e o de Curiosas. Nesta classificação considerou-se a finalidade preponderante do curso, pois, em alguns deles havia elementos sem experiência anterior junto com o pessoal já em função. O curso de Metodologia de Pesquisa foi destinado a enfermeiras. Para as outras, 5 denominações foram exigidos 6 a 9 anos de estudo em 15 cursos $(65,4 \%)$ : o de Visitadoras, o de Primeiros Socorros, e de. Instrumentação Cirúrgica e 12 dos de atendentes $(66,7 \%)$. Nos outros 6 cursos de atendentes foram exigidos 5 anos de estudos ou menos; para o Curso de Curiosas não há informação.

\section{T A B E L A 3}

A parte prática dos cursos ocupou de $90 \%$ da carga horária, no Curso de Instrumentação Cirúrgica, a $50 \%$, no de Metodologia de Pesquisa; os Cursos de Atendentes ocuparam em média 68,7\% do tempo com a parte prática, com variações de 40 a $80 \%$; o Curso de Primeiros Socorros não distribuiu as horas entre a teoria e a prática. Os Cursos mais intensivos foram os de Atendentes, com uma carga horária semanal média de 35 horas, e o de Visitadoras com 33 horas; o menos intensivo foi o de Metodologia de Pesquisa, com 2 horas semanais.

\section{T A B E L A S 4 e 5}

21 dos cursos realizados foram avaliados de alguma maneira; 2 não responderam o quesito. Em $19(82,6 \%)$ houve provas escritas e práticas; em $5(21,7 \%)$ os alunos apresentaram relatório e em $21(91,3 \%)$, a Coordenadora do Curso elaborou relatório. No Curso de Visitadoras foram utilizados os 4 tipos de avaliação. Nos 
de Atendentes, exceto 1, que não informou sobre o item, em todos houve provas escritas, práticas e relatório da Coordenadora.

O preço da hora-aula mais baixo foi o do Curso de Visitadoras $(\mathrm{Cr} \$ 12,00)$ e o mais alto foi o de Metodologia da Pesquisa $(\mathrm{Cr} \$$ $75,00)$; o custo médio de aulas para atendentes foi de $(\operatorname{Cr} \$ 14,00)$. O custo per-capita mais baixo ocorreu no curso de Primeiros Socorros $(\mathrm{Cr} \$ 13,00)$ e o mais alto no de Visitadoras $(\mathrm{Cr} \$ 1.761,00)$. O custo per-capita médio dos Cursos de Atendentes foi de $(\operatorname{Cr} \$ 250,00)$, (cálculo baseado nos 16 cursos que forneceram informação). O maior e o menor per-capita ocorreram na Guanabara ( $\mathrm{Cr} \$ 360,00$ e 180,00). O gasto para esses 16 cursos foi de $(\operatorname{Cr} \$ 74.772,00)$. O gasto total apurado foi de $(\operatorname{Cr} \$ 115.747,00)$, para 21 cursos.

\section{COMENTÁRIO}

Apesar de havermos obtido resposta de apenas metade das Seções, julgamos poder afirmar que a atuação da ABEn junto ao PIPIIO, através das suas Seções Estaduais, se faz de modo muito desigual e que esta ação deveria ser incrementada na grande maioria delas. A recomendação feita pela Presidente da ABEn na Assembléia de Delegados de 1970 vem sendo parcialmente seguida;

- cerca de $80 \%$ do esforço despendido pelas Seções tem como objeto o atendente, o que deve corresponder a uma necessidade do mercado de trabalho. Mais de $80 \%$ do pessoal preparado em todos os cursos já se encontravam em função, o que deve corresponder ao reconhecimento, por parte das chefias dos Serviços de Saúde, da necessidade de melhorar o padrão assistencial prestado pelas mesmas. Em relação aos atendentes este percentual é de cerca de $95 \%$;

- parece haver um esforço no sentido de melhorar a escolaridade do pessoal utilizado nos Serviços de Enfermagem, visto que, com exceção feita às curiosas, apenas 33 alunos, todos atendentes, cerca de $10 \%$ do total desta categoria, foram treinados com menos que o primário completo;

- há um consenso de que esses cursos devem ser eminentemente práticos, pois grande parte da carga horária foi destinada a estes aspectos e, de modo geral, os cursos seguiram o espírito do PIPMO, em relação à intensividade; 
- sente-se a necessidade de formulação de normas para a elaboração dos projetos dos cursos, de morlo a que possa haver maior racionalização dos recursos (expressa principalmente na carga horária, no tamanho das turmas, na intensividade e nos custos) e padronização dos certificados conferidos ao pessoal treinado, pois, atualmente, denominações iguais abrangem cursos bastante diferentes entre si.

\section{RECOMENDAÇÃO}

Que as Seções da ABEn procurem incrementar sua atuação junto ao PIPMO e que esta ação seja coordenada pela ABEn Central.

\section{REFERENCIAS}

1 - PRESIDENCIA DA REPúBLICA. Metas e Bases para a Ação do Governo. Rio, setembro de 1970 .

2 - REVISTA BRASIlleIRA DE ENFERMAGEM. Números 1 e 2 jan., mar., 1971, pág. 128.

3 LIVRO DE ATAS DAS REUNIÕES DA DIRETORIA DA ABEn $1 .^{\mathrm{a}}$ Reunião Ordinária - 12 de março de 1971 - pág. 48 anverso

2. ${ }^{\natural}$ Reunião Ordinária -7 de maio de 1971 - pág. 51 verso

1. ${ }^{2}$ Reunião Ordinária -18 de março de 1972 - pág. 62 verso

4 - LIVRO DE ATAS DAS ASSEMBLEIAS DE DELEGADOS DA ABEn. Ata da A.D. de 1971, Manaus. 
NÚMERO E PERCENTUAL DE CURSOS, CARGA HORARIA E ALUNOS, SEGUNDO A SEÇÃO DA ABEN NOS DIVERSOS ESTADOS DO PAfS.

BRASIL, MAIO DE 1971 A MAIO DE 1972

\begin{tabular}{|c|c|c|c|c|c|c|c|}
\hline \multirow{2}{*}{$\begin{array}{l}\text { N. } .^{\text {de }} \\
\text { ordem }\end{array}$} & \multirow[b]{2}{*}{ Seções } & \multicolumn{2}{|c|}{ Cursos } & \multicolumn{2}{|c|}{ Carga horária } & \multicolumn{2}{|c|}{ Alunos } \\
\hline & & N. 9 & $\%$ & N.9 & $\%$ & N.9 & $\%$ \\
\hline 1 & $\mathbf{A M}$ & $\cdots$ & & & & & \\
\hline 2 & PA & - & & & & & \\
\hline 3 & MA & $\cdots$ & & & & & \\
\hline 4 & PI & $\cdots$ & & & & & \\
\hline 5 & CE & $\ldots$ & & & & & \\
\hline 6 & $\mathbf{R N}$ & 1 & 4.3 & 520 & 7.2 & 30 & 7.2 \\
\hline 7 & PB & $\cdots$ & & & & & \\
\hline 8 & PE & - & & . & & & \\
\hline 9 & AL & 1 & 4.3 & 40 & 0.6 & 18 & 4.3 \\
\hline 10 & SE & 4 & 17.4 & 2.291 & 31.9 & 49 & 11.8 \\
\hline 11 & BA & - & & & & & \\
\hline 12 & GB & 3 & 13.0 & 301 & 4,2 & 41 & 10.0 \\
\hline 13 & RJ & $13 x$ & 56.7 & 4.000 & 55.8 & 246 & 59.5 \\
\hline 14 & SP & $\cdots$ & & & & & \\
\hline 15 & PR & $\cdots$ & & & & & \\
\hline 16 & SC & 1 & 4.3 & 20 & 0.3 & 30 & 7.2 \\
\hline 17 & RS & - & & & & & \\
\hline 18 & MG & $\cdots$ & & & & & \\
\hline 19 & MT & $\cdots$ & & & & & \\
\hline 20 & GO & $\cdots$ & & & & & \\
\hline 21 & DF & $\cdots$ & & & & & \\
\hline Total & 10 & 23 & 100 & 7.172 & 100 & 414 & 100 \\
\hline
\end{tabular}

(*) Os cursos ministrados em duas turmas foram computados como 2 cursos. 


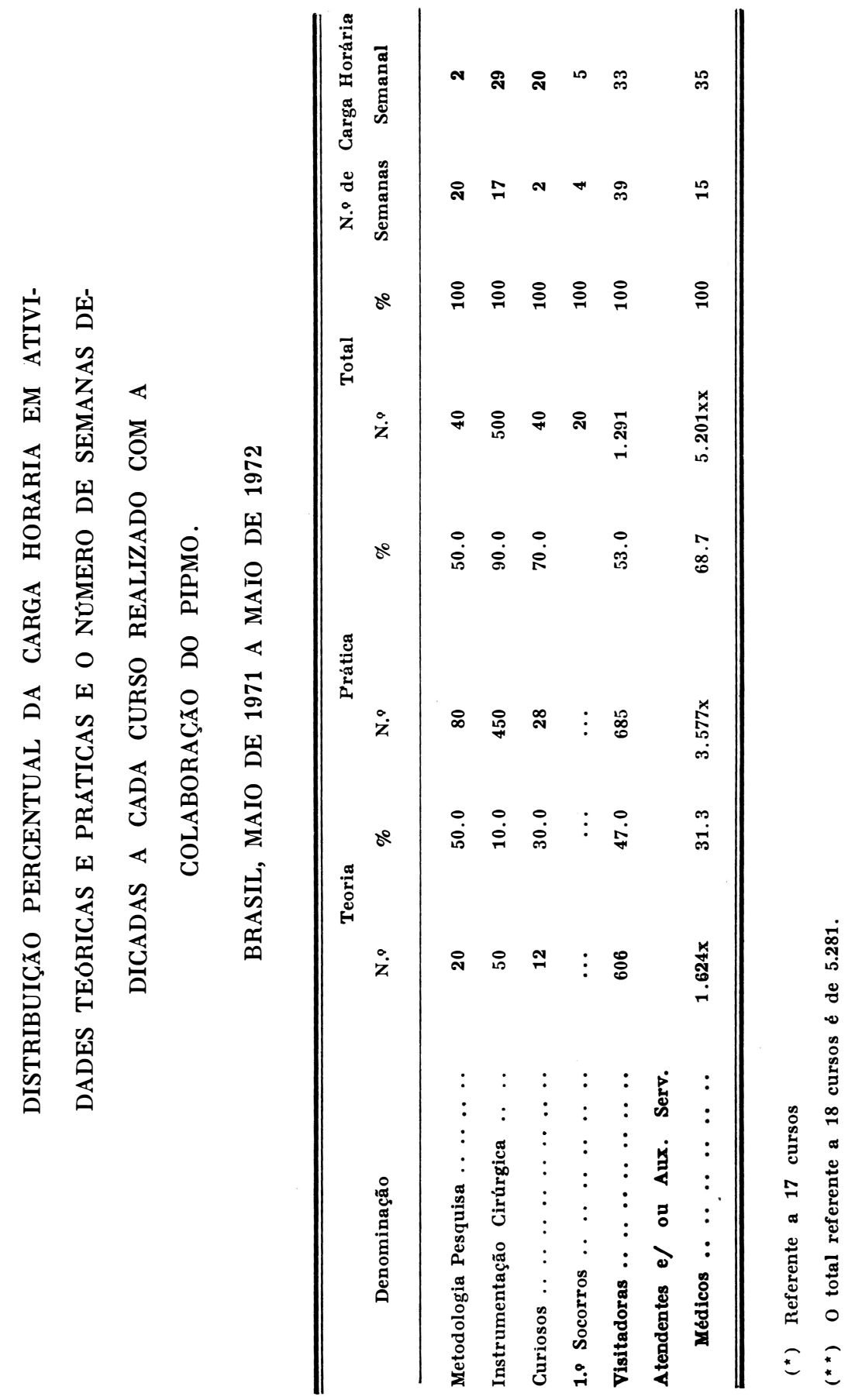




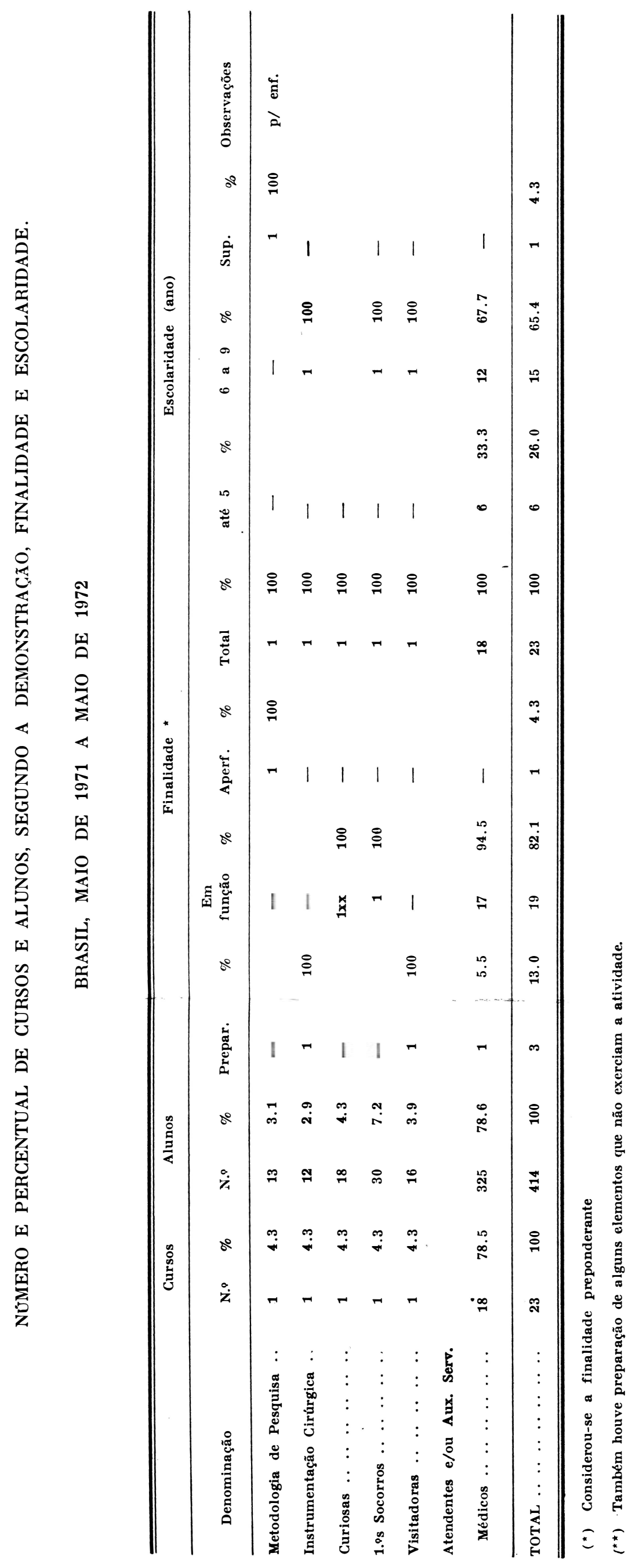




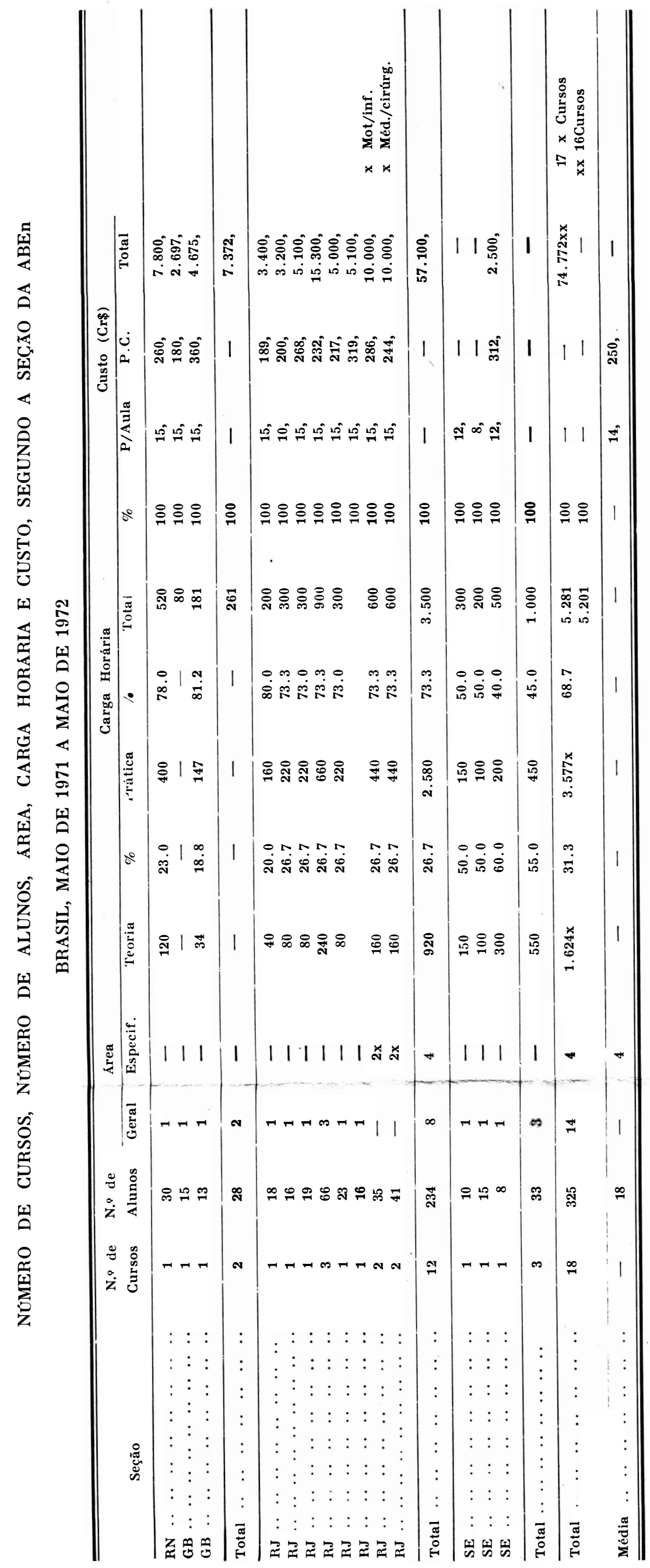




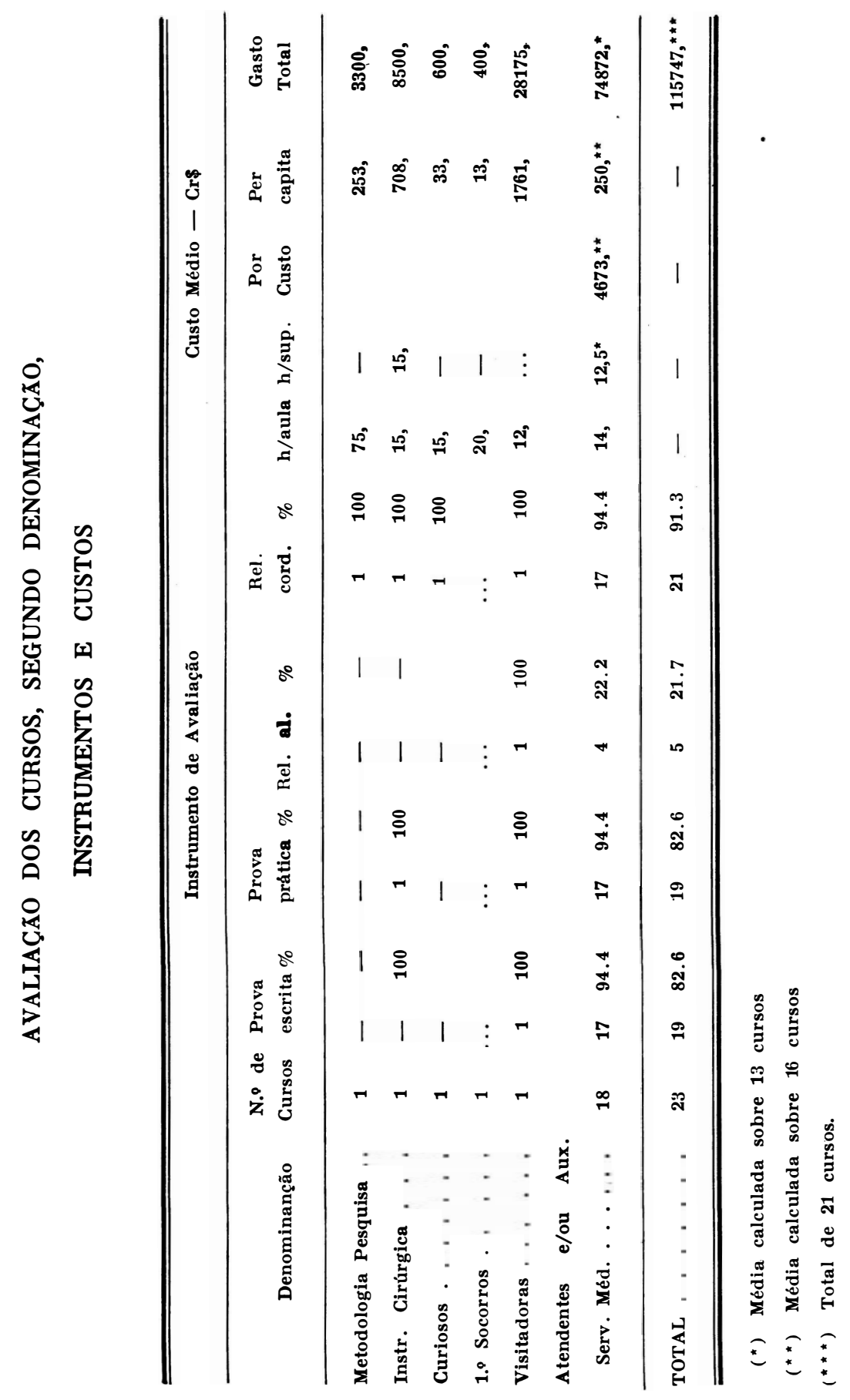

